\title{
MELTING HEAT TRANSFER AND MHD BOUNDARY LAYER FLOW OF EYRING-POWELL NANOFLUID OVER A NONLINEAR STRETCHING SHEET WITH SLIP
}

\author{
N. VIJAYA BHASKAR REDDY* \\ Government Degree College (Autonomous) \\ Siddipet Dist., Telangana, INDIA, 502103 \\ E-mail: vijju.reddy20@gmial.com \\ N. KISHAN \\ Department of Mathematics \\ University College of Science, Osmania University \\ Hyderabad, INDIA, 500007 \\ C. SRINIVAS REDDY \\ Government Degree College \\ Mulugu, Warangal Dist., Telangana, INDIA, 506343
}

\begin{abstract}
The steady laminar incompressible viscous magneto hydrodynamic boundary layer flow of an Eyring- Powell fluid over a nonlinear stretching flat surface in a nanofluid with slip condition and heat transfer through melting effect has been investigated numerically. The resulting nonlinear governing partial differential equations with associated boundary conditions of the problem have been formulated and transformed into a non-similar form. The resultant equations are then solved numerically using the Runge-Kutta fourth order method along with the shooting technique. The physical significance of different parameters on the velocity, temperature and nanoparticle volume fraction profiles is discussed through graphical illustrations. The impact of physical parameters on the local skin friction coefficient and rate of heat transfer is shown in tabulated form.
\end{abstract}

Key words: Eyring-Powell fluid, melting heat transfer, MHD, nanofluid, stretching sheet, Brownian motion, thermophoresis.

\section{Introduction}

The study of heat transfer over a stretching surface is of significant importance due to numerous applications in industrial and technological processes such as cooling of metallic plates, glass fibers, extrusion of polymer sheets and boundary layer along liquid films in concentration processes, paper production and metal spinning. The rate of heat transfer at the stretching surface affects deeply the quality of the final products which must fulfill the desired specifications. Crane [1] was the first who studied a two dimensional stretching surface in a quiescent fluid. After this pioneering work, the flow field over a stretching surface has drawn considerable attention and a good amount of literature has been generated on this problem [2-9].

The mathematical formulation for flows of non-Newtonian fluids in general is more complex. The most frequently used models of non-Newtonian models are the second grade fluids e.g. Maxwell, Oldroyd-B and power law. A broad description of the behaviour in both steady and unsteady flow situations, together with mathematical models can be found in [10-17]. The Powell-Eyring model has certain advantages over

\footnotetext{
* To whom correspondence should be addressed
} 
the other non-Newtonian fluid models. Firstly, it is deduced from the kinetic theory of liquids rather than the empirical relation. Secondly, it correctly reduces to Newtonian behaviour for low and high shear rates. The study of a Powell-Eyring fluid has attracted the researchers of fluid dynamics due to its numerous applications in science and technology. Patel and Timol [18] numerically examined the flow of a PowellEyring model through asymptotic boundary conditions. Hayat et al. [19] studied the steady flow of a PowellEyring fluid over a moving surface with convective boundary conditions. Flow and heat transfer of a PowellEyring fluid over a shrinking surface in a parallel free stream is presented by Rosca and Pop [20]. Jalil et al. [21] studied the flow and heat transfer of a Powell-Eyring fluid over a moving surface in a parallel free stream. The problem of a slider bearing lubricated with Eyring Powell fluid is presented numerically using the homotopy perturbation analysis by Islam et al. [22]. Regarding the study of Powell-Eyring on fluid flow and heat transfer, some former study of Powell-Eyring fluid flow have been presented in the works [23-24]. The flow and heat transfer of a Powell-Eyring fluid over a continuously moving surface in the presence of a free stream velocity is investigated by Hayat et al. [25].

Due to the small size and very large specific surface areas of nanoparticles, nanofluids have superior properties such as high thermal conductivity, minimal clogging in flow passages, long-term stability, and homogeneity. Thus, nanofluids have a wide range of potential applications in electronic cooling, drug administration mechanisms, peristaltic pumps for diabetic patients, solar collectors and nuclear applications. Based on these real world applications, Choi [26] introduced the concept of nanofluid in order to develop advanced heat transfer fluids with substantially higher conductivities. Later on, the boundary layer flow of a nanofluid past a stretching surface under the effect of Brownian motion and thermophoresis was investigated by Khan and Pop [27]. Kuznetsov and Nield [28] investigated the natural convective boundary-layer flow of a nanofluid past a vertical plate by incorporating Brownian motion and thermophoresis effects. Gorla et al. [29] reported the numerical solutions for a steady boundary layer flow of a nanofluid on a stretching circular cylinder in a stagnant free stream.

A significant number of studies have applied the no-slip boundary conditions at the wall. However, the no-slip assumption is not applicable when a fluid flows in micro and nano channels and it must be replaced by slip boundary conditions (Aziz [30]). Nield and Kuznetsov [31] presented an analytic solution for a convection flow in channel or circular ducts saturated with a rarefied gas in a slip-flow regime. Beavers and Joseph [32] investigated fluid flow over a permeable wall with a slip boundary condition. The effects of a second order velocity-slip and temperature-jump on basic gaseous fluctuating micro-flows were analysed by Hamdan et al. [33]. The effects of partial slip on a steady boundary layer stagnation-point flow of an incompressible fluid and heat transfer from a shrinking sheet were investigated by Bhattacharyya et al. [34].

Melting and solidification play a vital role in the advanced technology process. Researchers are interested in exploring melting heat transfer due to a wide range of applications of the melting phenomenon of solid-liquid phase change in the welding process, crystal growth, thermal protection, heat transportation, melting of permafrost, preparation of semiconductors material and the casting of a manufacturing process. Initially, Robert [35] described the melting phenomenon of ice slab placed in a hot air stream. A boundary layer stagnation point flow of a Maxwell fluid towards a stretching sheet with the melting phenomenon is analyzed by Hayat et al. [36]. Das [37] discussed the melting phenomenon in the magneto hydrodynamic flow over a moving surface with thermal radiation. Melting heat transfer in a steady laminar flow over a stationary flat plate was studied by Epstein and Cho [38]. Then Kazmierczak et al. [39] studied the steady convection flow over a flat plate embedded in a porous medium with the melting heat transfer effect. Gorla et al. [40] studied the melting heat transfer in a mixed convection flow over a vertical plate. Recently, Bachok et al. [41] analized a steady two-dimensional stagnation point flow and heat transfer over a melting stretching sheet. Anuar Ishak, Roslinda Nazar et al. [42] studied the laminar boundary layer flow and heat transfer from a warm, laminar liquid flow to a melting surface moving parallel to a constant free stream. Gireesha et al. [43] investigated the effects of melting heat transfer in boundary layer stagination-point flow of a nanofluid toward a stretching surface with heat source/sink and magnetic field.

Over the last few years, a considerable amount of experimental and theoretical work has been carried out to determine the role of natural convection in the kinetics of heat transfer accompanied with the melting or solidification effect. Processes involving melting heat transfer in non-Newtonian fluids have promising 
applications in thermal engineering, such as oil extraction, magma, solidification, melting of permafrost, geothermal energy recovery, silicon wafer process, thermal insulation, etc. Chamkha et al. [44] analysed the effect of a transverse magnetic field on a hydro magnetic, forced convection flow with heat and mass transfer of a nanofluid over a horizontal stretching plate under the influence of melting and heat generation or absorption. Gorla et al. [45] presented a boundary layer analysis for a warm and laminar flow of a nanofluid over a melting surface moving parallel to a uniform free stream.

Recently, Panigrahi et al. [46] studied the analytical self-similar solution of the mixed convection flow of a non-Newtonian Powell Eyring fluid over a nonlinear stretching vertical permeable surface in the presence of a magnetic field. Even though considerable progress has been made on flow phenomena over a stretching sheet, still more work is needed to understand the effect of melting involving different non-Newtonian models. The paper focuses on the study of a non-Newtonian Powell Eyring fluid over a melting stretching permeable vertical surface in the presence of a magnetic field, in this study the velocity slip conditions are included. A suitable transformation is used to transform the partial differential equations to a system of ordinary differential equations together with boundary conditions. The resulting system of ordinary differential equations is solved using the well-known Runge-Kutta technique along with the shooting method.

\section{Mathematical formulation}

Let us consider a two dimensional magneto hydrodynamic flow of an incompressible Powell-Eyring nanomaterial. The flow is caused by a nonlinear stretching surface. Features of thermophoresis and Brownian motion are taken into consideration. The $x$-axis and $y$-axis are taken parallel and transverse to the stretching surface. The sheet at $y=0$ is stretching along the $\mathrm{x}$-direction with velocity $u_{w}(x)=c x^{n}$ where $c$ and $n$ are positive constants. The Powell-Eyring fluid is electrically conducted subject to a non-uniform magnetic field applied in the $y$-direction. It is assumed that the temperature of the melting surface is $T_{m}$ while the temperature at the free stream is $T_{\infty}$ such that $T_{\infty}>T_{m}$. Further, it is assumed that the magnetic Reynolds number is small so that the induced magnetic field is neglected and that the heat generation or absorption effect is based on the difference between the local and melting temperatures. Assumptions of a low magnetic Reynolds number and boundary layer approximation are employed in the mathematical development. The extra stress tensor for the Powell-Eyring fluid is

$$
\tau_{i j}=\mu \frac{\partial u_{i}}{\partial x_{j}}+\frac{1}{\beta} \sinh ^{-1}\left(\frac{1}{c_{1}} \frac{\partial u_{i}}{\partial x_{j}}\right)
$$

In which $\mu$ stands for the dynamic viscosity and $\beta$ and $c_{1}$ for material constants. The Taylor expansion for the inverse hyperbolic term in the above equation is

$$
\sinh ^{-1}\left(\frac{1}{c_{1}} \frac{\partial u_{i}}{\partial x_{j}}\right) \cong \frac{1}{c_{1}} \frac{\partial u_{i}}{\partial x_{j}}-\frac{1}{6}\left(\frac{1}{c_{1}} \frac{\partial u_{i}}{\partial x_{j}}\right)^{3}, \quad\left|\frac{1}{c_{1}} \frac{\partial u_{i}}{\partial x_{j}}\right| \ll 1 .
$$

The boundary layer expressions for the two-dimensional magneto hydrodynamic flow of the PowellEyring nanofluid are

$$
\frac{\partial u}{\partial x}+\frac{\partial v}{\partial y}=0
$$




$$
\begin{aligned}
& u \frac{\partial u}{\partial x}+v \frac{\partial u}{\partial y}=v \frac{\partial^{2} u}{\partial y^{2}}+\frac{1}{\rho \beta c_{1}} \frac{\partial^{2} u}{\partial y^{2}}-\frac{1}{2 \rho \beta c_{1}^{3}}\left(\frac{\partial u}{\partial y}\right)^{2} \frac{\partial^{2} u}{\partial y^{2}}+ \\
& -\frac{\sigma}{\rho} B^{2}(x) u+g \beta_{T}\left(T-T_{\infty}\right)+g \beta_{c}\left(C-C_{\infty}\right), \\
& u \frac{\partial T}{\partial x}+v \frac{\partial T}{\partial y}=v \frac{\partial^{2} T}{\partial y^{2}}+\tau\left[D_{B} \frac{\partial C}{\partial y} \frac{\partial T}{\partial y}+\frac{D_{T}}{T_{\infty}}\left(\frac{\partial T}{\partial y}\right)^{2}\right], \\
& u \frac{\partial C}{\partial x}+v \frac{\partial C}{\partial y}=D_{B} \frac{\partial^{2} C}{\partial y^{2}}+\frac{D_{T}}{T_{\infty}} \frac{\partial^{2} T}{\partial y^{2}}
\end{aligned}
$$

Here $u$ and $v$ show the velocity components along the horizontal and vertical directions, $B(x)=B_{0} x^{\frac{n-1}{2}}$ represents the non-uniform magnetic field, $v\left(=\frac{\mu}{\rho_{f}}\right)$ stands for the kinematic viscosity, $\rho_{f}$ for density of the base liquid, $\sigma$ for the electrical conductivity, $T$ for temperature, $C$ for the nanoparticle volume fraction, $\tau=\frac{(\rho c) p}{(\rho c)_{f}}$ is the ratio between the effective heat capacity of the nanoparticle material and heat capacity of the fluid, $c$ is the volumetric volume expansion coefficient and $\rho_{p}$ is the density of the particles, $\alpha=k /\left(\rho c_{f}\right)$ for the thermal diffusivity of fluid, $k$ for the thermal conductivity, $D_{T}$ for the thermophoretic diffusion constant, $D_{B}$ for the Brownian diffusivity and $T_{\infty}$ for ambient fluid temperature. The associated boundary conditions are

$$
\begin{aligned}
& u=U_{w}+U_{\text {slip }}, \quad T=T_{m}=\mathrm{T}_{\infty}+\mathrm{ax}^{r}, \quad D_{B} \frac{\partial C}{\partial y}+\frac{D_{T}}{T_{\infty}} \frac{\partial T}{\partial y}=0 \quad \text { at } \quad y=0, \\
& u \rightarrow 0, \quad T \rightarrow T_{\infty}, \quad C \rightarrow C_{\infty} \quad \text { as } \quad y \rightarrow \infty,
\end{aligned}
$$

and

$$
k\left(\frac{\partial T}{\partial y}\right)_{y=0}=\rho\left[\lambda+C_{S}\left(T_{m}-T_{0}\right)\right] v(x, 0)
$$

$$
U_{\text {slip }}=\gamma\left(\frac{\partial u}{\partial y}+\frac{1}{\mu \beta c_{1}} \frac{\partial u}{\partial y}-\frac{1}{6 \mu \beta c_{1}^{3}}\left(\frac{\partial u}{\partial y}\right)^{3}\right)
$$

and $u_{w}(x)=c x^{n}$; here $c$ shows the rate of the stretching surface, $\gamma$ is the slip coefficient having dimension of length, $T_{m}$ is the temperature of the stretching surface, $n$ is the power-law index and $C_{\infty}$ is the ambient fluid concentration, Further, $k$ is the thermal conductivity, $\lambda$ is the latent heat of the fluid and $C_{S}$ is the heat capacity of the solid surface. 
Equation (2.7) states that the heat conducted to the melting surface is equal to the heat of melting plus the sensible heat required to raise the solid surface temperature $T_{0}$ to its melting temperature $T_{m}$. (see Epstein and Cho [38])

Introducing the following similarity transformations

$$
\begin{aligned}
& u=c x^{n} f^{\prime}(\eta), \quad v=-\sqrt{\frac{\mathrm{c} v(n+1)}{2}} x^{\frac{n-1}{2}}\left(f+\frac{n-1}{n+1} \eta f^{\prime}\right), \\
& \eta=y \sqrt{\frac{(n+1) c}{2 v}} x^{\frac{n-1}{2}}, \quad \theta(\eta)=\frac{T-T_{\infty}}{T_{m}-T_{\infty}}, \quad \phi(\eta)=\frac{C-C_{\infty}}{C_{\infty}}
\end{aligned}
$$

by using similarity transformations Eqs (2.1), (2.2), (2.4) and (2.6) reduces to

$$
\begin{aligned}
& (1+\varepsilon) f^{\prime \prime \prime}+f f^{\prime \prime}-\frac{2 n}{n+1} f^{\prime 2}-\frac{n+1}{2} \varepsilon \delta f^{\prime \prime 2} f^{\prime \prime \prime}-\frac{2}{n+1}\left[M f^{\prime}-\operatorname{Gr} \theta-\mathrm{Gc} \phi\right]=0, \\
& \frac{1}{\operatorname{Pr}} \theta^{\prime \prime}+f \theta^{\prime}-\frac{2 r}{n+1} f^{\prime} \theta+N b \theta^{\prime} \phi^{\prime}+N t \theta^{\prime 2}=0, \\
& \phi^{\prime \prime}+\operatorname{Le} \operatorname{Pr} f \phi^{\prime}+\frac{N t}{N b} \theta^{\prime \prime}=0,
\end{aligned}
$$

and the boundary conditions are

$$
\begin{aligned}
& \operatorname{Pr} f[0]+M e \theta^{\prime}[0]=0, \quad f^{\prime}[0] \breve{\mathrm{S}} 1+\zeta\left((1+\varepsilon) f^{\prime \prime}[0]-\left(\frac{\varepsilon \delta}{3}\right) *\left(\frac{n+1}{2}\right) f^{\prime \prime}[0]^{3}\right), \quad \theta[0]=1, \\
& N b \phi^{\prime}[0]+N t \theta^{\prime}[0]=0, \quad f^{\prime}[\infty] \rightarrow 0, \quad \theta[\infty] \rightarrow 0, \quad \phi[\infty] \rightarrow 0 .
\end{aligned}
$$

Here $\varepsilon$ and $\delta$ stand for fluid parameters, $\zeta$ is the slip velocity parameter, Pr stands for the Prandtl number, $M e$ is the dimensionless melting parameter, $M$ is the magnetic parameter, Gr is the thermal Grashof number, Gc is the solutal Grashof number, $N t$ stands for the thermophoresis parameter, $N b$ for the Brownian motion parameter and Le for the Lewis number. These parameters are defined by

$$
\begin{aligned}
& \varepsilon=\frac{1}{\mu \beta_{1} c_{1}} \text { where }\left(v=\frac{\mu}{\rho}\right), \quad \delta=\frac{u_{w}^{3}}{2 v x c_{1}^{2}}, \quad M e=\frac{c_{p}\left(T_{\infty}-T_{m}\right)}{\lambda+c_{S}\left(T_{m}-T_{0}\right)}, \quad \zeta=\gamma \sqrt{\frac{(n+1) c}{2 v}} x^{\frac{n-1}{2}}, \\
& \operatorname{Pr}=\frac{v}{\alpha}, \quad N t=\frac{\tau D_{T}\left(T_{m}-T_{\infty}\right)}{T_{\infty} v}, \quad N b=\frac{\tau D_{B} C_{\infty}}{v}, \quad \mathrm{Le}=\frac{\alpha}{D_{B}}, \quad \mathrm{Gr}=\frac{g \beta_{T}\left(T_{m}-T_{\infty}\right)}{c^{2} x^{2 n-1}}, \quad \mathrm{Gc}=\frac{g \beta_{C} C_{\infty}}{c^{2} x^{2 n-1}},
\end{aligned}
$$

with $c_{p}$ being the specific heat of the fluid at constant pressure. It is worth mentioning that the melting parameter $M e$ is a combination of the Stefan numbers $c_{p}\left(T_{\infty}-T_{m}\right) / \lambda$ and $c_{S}\left(T_{m}-T_{0}\right) / \lambda$ for the liquid and solid phases, respectively. 
Expressions for the local skin friction coefficient $C_{f_{x}}$ and local Nusselt number $\mathrm{Nu}_{x}$ are defined as

$$
C_{f_{x}}=\frac{\tau_{w}}{\rho U_{w}^{2}}, \quad \mathrm{Nu}_{x}=\frac{X q_{w}}{k_{\infty}\left(T_{m}-T_{\infty}\right)}
$$

where $k_{\infty}$ is the thermal conductivity of the nanofluid, in which $\tau_{w}$ the wall shear stress and $q_{w}$ is the wall heat flux, given by

$$
\begin{aligned}
& \tau_{w}=\left[\left(1+\frac{1}{\mu \beta c_{1}}\right) \frac{\partial u}{\partial y}-\frac{1}{6 \mu \beta c_{1}^{3}}\left(\frac{\partial u}{\partial y}\right)^{3}\right]_{y=0}, \\
& q_{w}=-k_{\infty}\left(\frac{\partial T}{\partial y}\right)_{y=0},
\end{aligned}
$$

applying similarity transformations (2.9), the skin friction coefficient and Nusselt number are converted to

$$
\begin{aligned}
& \operatorname{Re}_{x}^{1 / 2} C_{f_{x}}=\sqrt{\frac{(n+1)}{2}}\left\{(1+\varepsilon) f^{\prime \prime}[0]-\left(\frac{\varepsilon \delta}{3}\right) *\left(\frac{n+1}{2}\right) * f^{\prime \prime}[0]^{3}\right\}, \\
& \operatorname{Re}_{x}^{-1 / 2} \mathrm{Nu} x=-\sqrt{\frac{(n+1)}{2}} \theta^{\prime}[0]
\end{aligned}
$$

where $\operatorname{Re}_{x}=\frac{U_{w}(x) x}{v}$ is local the Reynolds number.

\section{Numerical results and discussion}

In this section, we discuss theoretically and show graphically the behavior of different physical quantities which are involved in the present flow problem. The set of Eqs (2.10)-(2.12) is highly nonlinear and coupled hence it cannot be solved analytically. The numerical solutions of Eqs (2.10)-(2.12) subject to the boundary conditions (2.13) are obtained using an efficient numerical shooting technique with a fourth order Runge-Kutta scheme. For the purpose of providing physical insight into the present problem, comprehensive numerical computations are carried out for various values of the flow parameters which describe the flow characteristics and the results are illustrated graphically. For computational purposes, the reason of integration $\eta$ is considerd as 0 to $\eta_{\infty}$ is equivalent to 8 , where $\eta_{\infty}$ corresponds to $\eta \rightarrow \infty$ which lies very well outside the momentum and thermal boundary layer. The present results are compared with these of Cortell [47], Rana and Bargava [48] and found in good agreement.

A representative set of graphical results for the velocity, temperature and nanoparticle volume fraction as well as the skin friction, local Nusselt number and local Sherwood number is presented and discussed for different flow parameter values. To verify the accuracy of the numerical results we compared our results with those given by Cortell [47], Rana and Bargava [48] as shown in Tab.1. The results are in excellent agreement. 
Table 1. Comparison for $-\theta^{\prime}(0)$ for various values of $n$. without nanoparticles and $\zeta=0, r=0, \mathrm{Gr}=0$, $\mathrm{Gc}=0$ and $M e=0$.

\begin{tabular}{|c|c|c|c|c|}
\hline $\operatorname{Pr}$ & $n$ & Cortell [47] & Rana and Bargava [48] & Present \\
\hline 1 & 0.2 & 0.610262 & 0.6113 & 0.610201 \\
\hline & 0.5 & 0.595277 & 0.5967 & 0.595200 \\
\hline & 1.5 & 0.574537 & 0.5768 & 0.574729 \\
\hline 5 & 0.2 & 1.607175 & 1.5910 & 1.607786 \\
\hline & 0.5 & 1.586744 & 1.5839 & 1.586782 \\
\hline & 1.5 & 1.557463 & 1.5496 & 1.557695 \\
\hline
\end{tabular}

Figures 1a-1c explains the effect of the melting parameter $M e$ on the velocity, temperature and nanoparticle volume fraction profiles. It is observed that for an increasing value of $M e$ the velocity and boundary layer thickness decrease. The temperature distribution decreases with an increasing melting parameter $M e$. This is because an increasing $M e$ with increasing the intensity of melting, which acts as blowing boundary conditions at the stretching surface and hence tends to thicken the boundary layer. Melting parameters reduce the nanoparticle volume fraction profile.

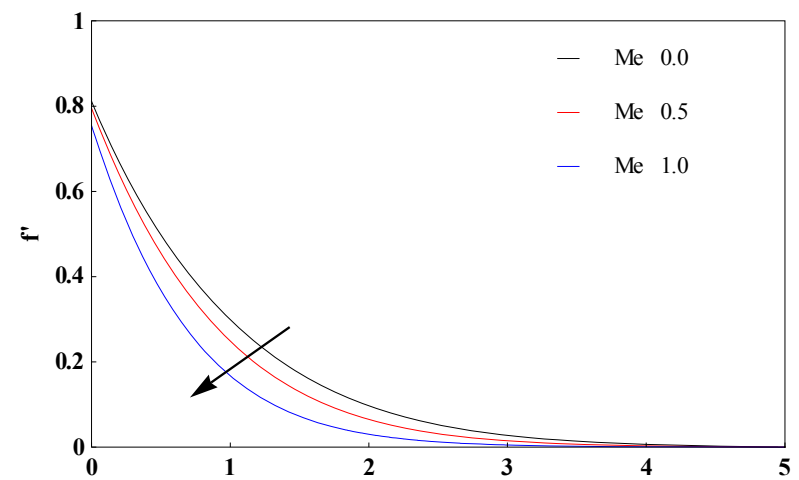

Fig.1a. Effect of the melting parameter on velocity profiles.

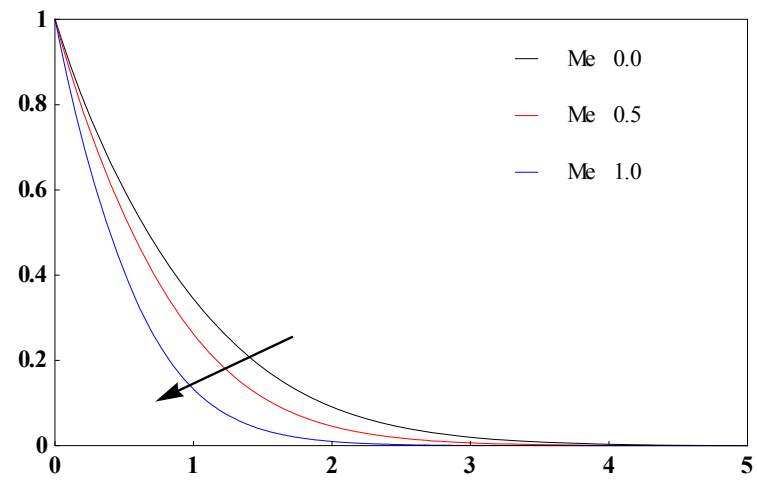

Fig.1b. Effect of the melting parameter on temperature profiles.

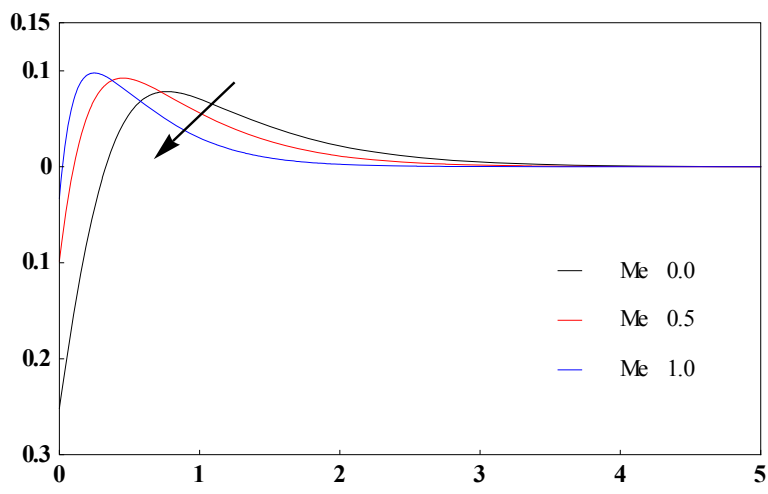

Fig.1c. Effect of the melting parameter on nanoparticle volume fraction profiles.

The influence of the slip velocity parameter $\zeta$ on the velocity, temperature and nanoparticle volume fraction is presented in Fig.2. We know that the slip velocity parameter decelerates the fluid flow along the surface. Hence the momentum boundary layer thickness decreases with an increasing slip velocity parameter 
$\zeta$. The effect of the slip velocity parameter $\zeta$ leads to enhancing temperature profiles. The nanoparticle volume fraction profiles increase with the increasing slip velocity parameter $\zeta$ away from the plate, while a reverse trend is noticed in the vicinity of the plate. The effects of the non-linear stretching parameter $n$ on the velocity, temperature and nanoparticle volume fraction are shown in Figs 3a-3c respectively. As an increasing nonlinear stretching sheet parameter $n$ decelerates the fluid velocity, it can be noticed that the temperature and nanoparticle volume fraction increases as increasing in the stretching sheet parameter $n$. Additionally, the temperature and nanoparticle volume fraction are dependent on the stretching sheet parameter.

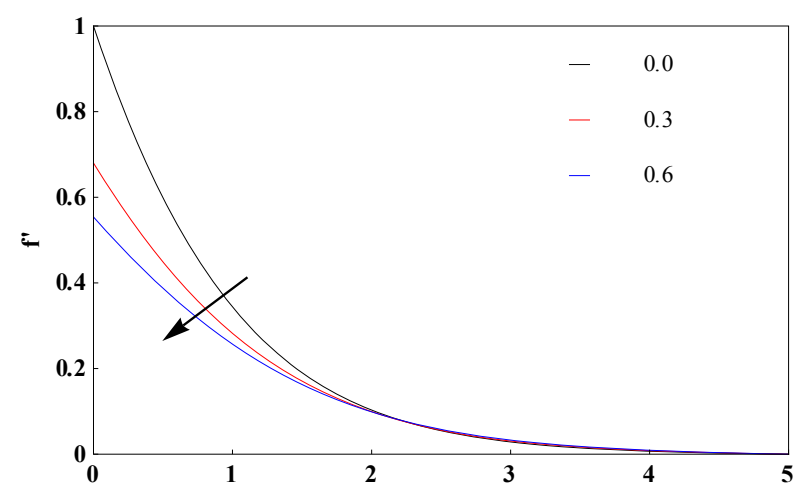

Fig.2a. Effect of the velocity slip parameter on Fig.2b. Effect of the velocity slip parameter on velocity profiles.

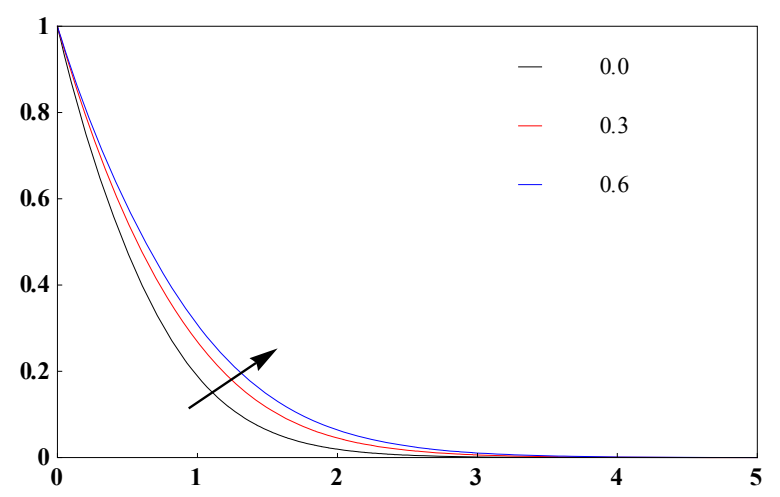
temperature profiles.

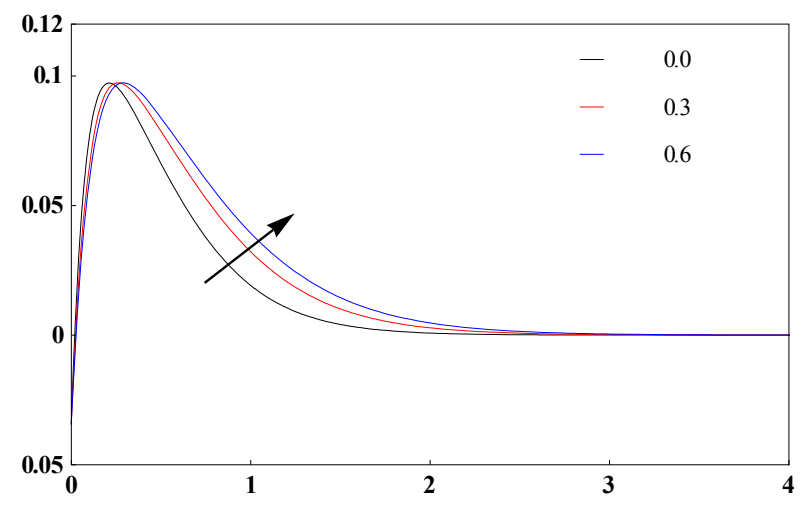

Fig.2c. Effect of the velocity slip parameter on nanoparticle fraction profiles.

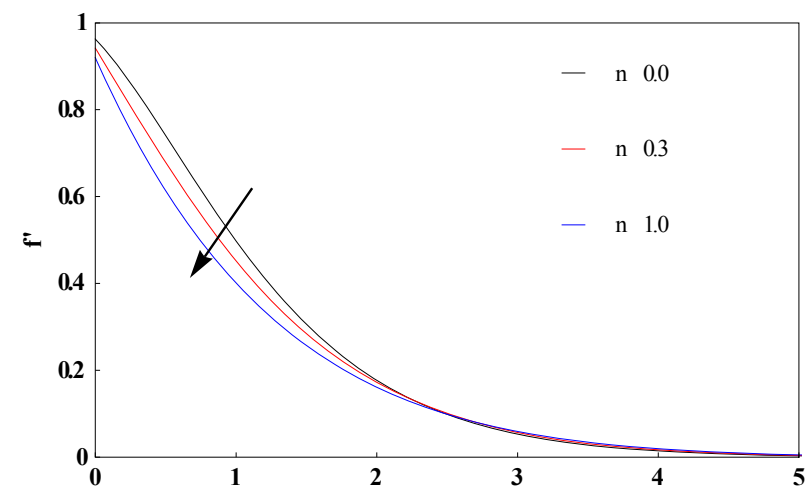

Fig.3a. Effect of the non-linear stretching parameter on velocity profiles.

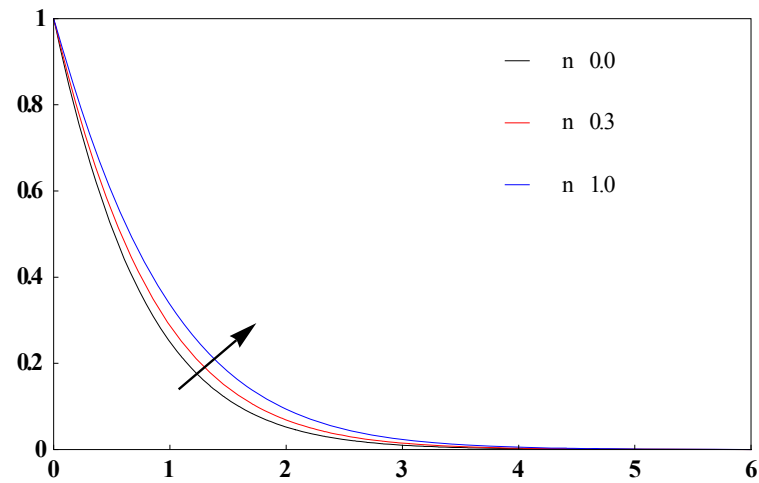

Fig.3b. Effect of the non-linear stretching parameter on temperature profiles. 


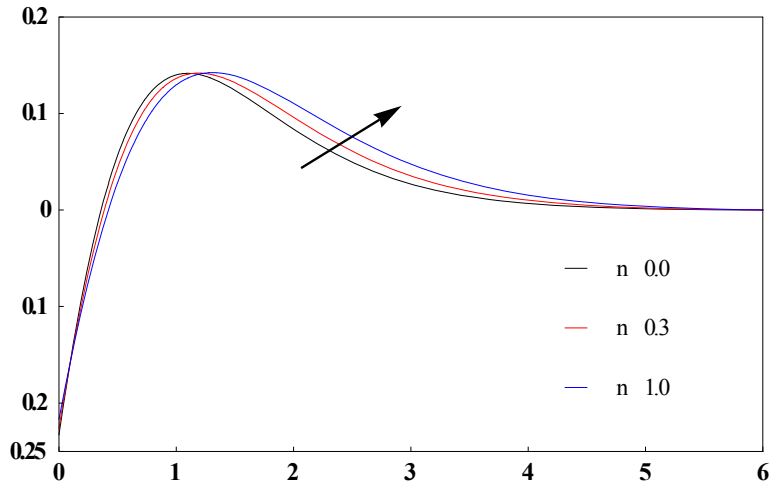

Fig.3c. Effect of the non-linear stretching parameter on nanoparticle volume fraction profiles.

Figures $4 a-4 c$ illustrate the effect of the Prandtl number $\operatorname{Pr}$ on the velocity, temperature and nanoparticle volume fraction. It is seen that the magnitude of the velocity gradient at the surface is higher for higher values of Pr. Thus the skin friction increases with an increase of Pr. It is observed that as increasing $\operatorname{Pr}$ is leading to decrease the temperature profiles as well as decreases the thermal boundary layer thickness. The nanoparticle volume fraction decreases with the increasing Prandtl number value. This is due to the fact that for small values of Pr are equivalent to larger values of thermal conductivities and therefore it is able to diffuse away from the stretching sheet.
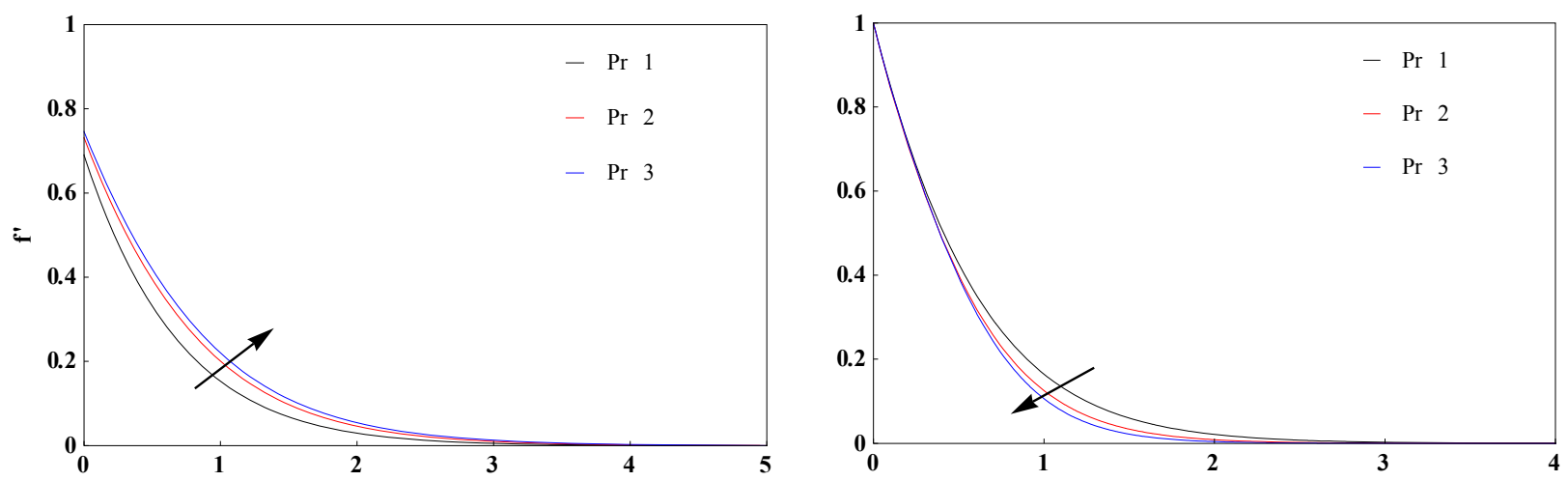

Fig.4a. Effect of the Prandtl number on velocity Fig.4b. Effect of the Prandtl number on temperature profiles. profiles.

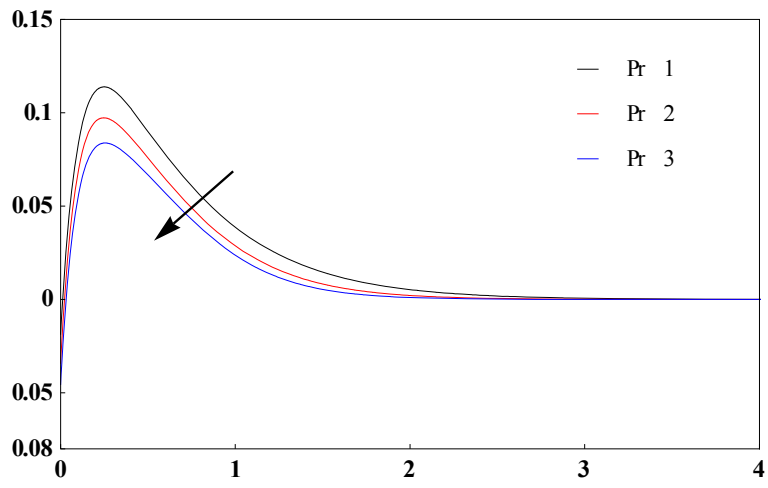

Fig.4c. Effect of the Prandtl number on nanoparticle volume fraction profiles. 
Figure 5 shows that when the Eyring-Powell parameter $\varepsilon$ increases, then the velocity profiles increase. Since the Eyring-Powell parameter $\varepsilon=\frac{1}{\rho \beta c_{l} v}$ so by increasing the Eyring-Powell parameter $\varepsilon$ the viscosity of the fluid, i.e, $\mu$, decreases which causes increasing velocity also fluid becomes less viscous for larger values of Eyring-Powell parameter $\varepsilon$ which enhances fluid velocity.

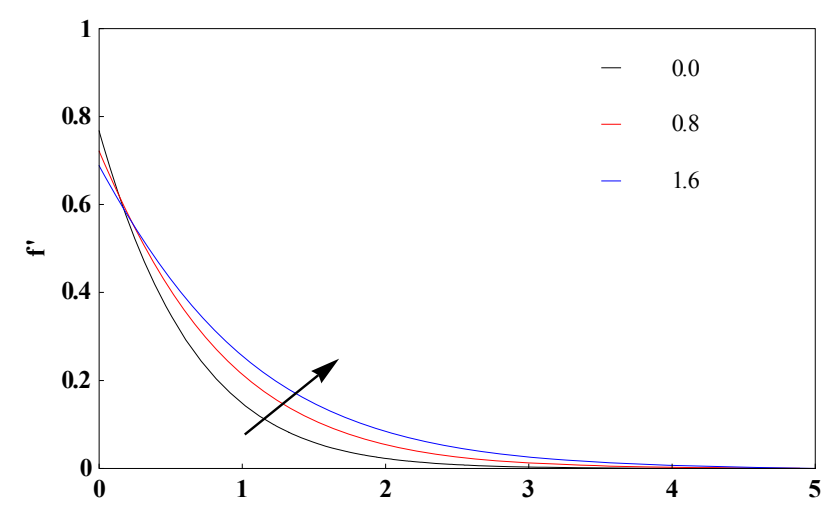

Fig.5. Effect of the Eyring-Powell fluid parameter on velocity profiles.

Figures 6a-6c show changes in the velocity, temperature and nanoparticle volume fraction profiles for different values of the magnetic field parameter $M$. When the magnetic field strength increases, the Lorentz force becomes stronger, which creates resistance in the motion of the fluid, so that the velocity profile decreases. It is noticed that the temperature and nanoparticle volume fraction profiles are increased with an increasing magnetic field parameter $M$.

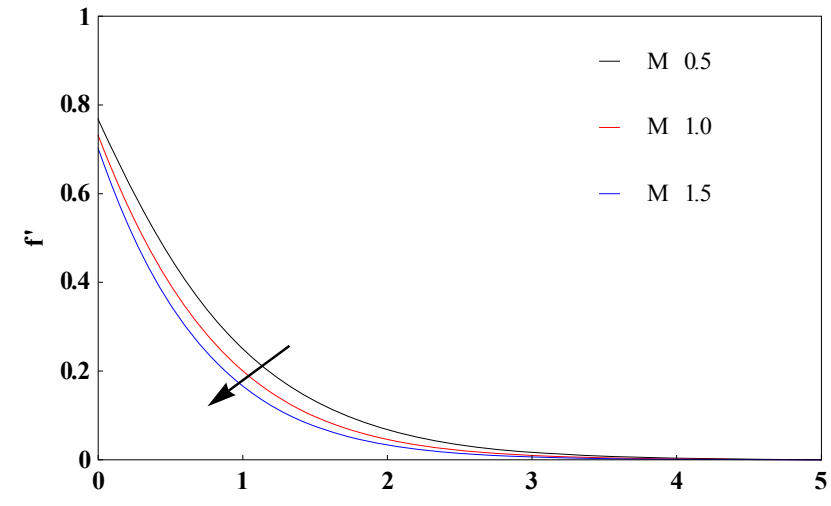

Fig.6a. Effect of the magnetic field parameter on velocity profiles.

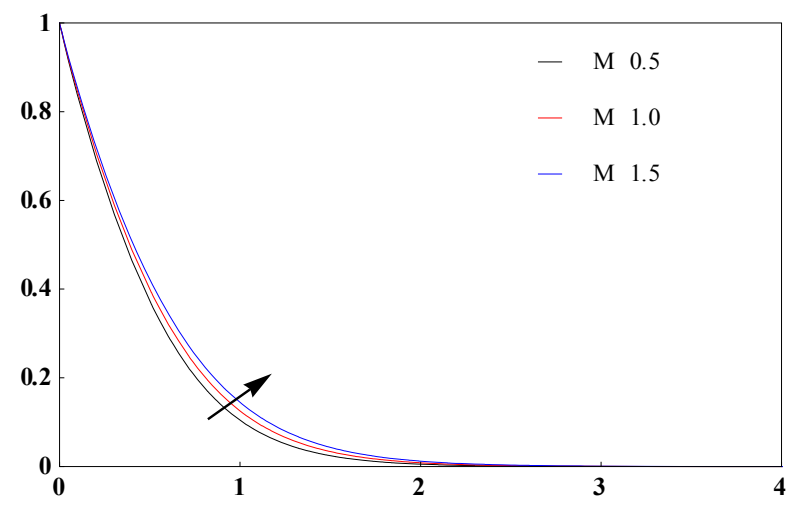

Fig.6b. Effect of the magnetic field parameter on temperature profiles. 


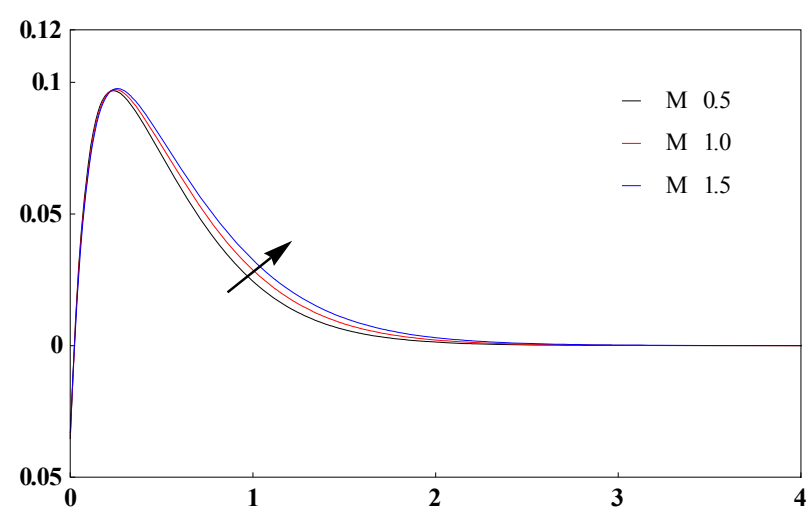

Fig.6c. Effect of the magnetic field parameter on nanoparticle volume fraction profile.

Figures $7 \mathrm{a}-7 \mathrm{c}$ reflect the effect of the thermophoresis parameter $N t$ on the velocity, temperature and nanoparticle volume fraction profiles, respectively. Thermophoresis mechanism in which small particles are pulled away from a hot surface to a cold surface due to this the transportation temperature of the fluid arises. Therefore the effect of the thermophoresis parameter $N t$ is to enhance the temperature and velocity profiles. It can be observed that an enhancement in the thermophoresis parameter $N t$ produces a force which leads to the movement of nanoparticles from a hot region to a cold region and hence the nanoparticle volume fraction increases with increasing the value of the thermophoresis parameter $N t$. Figure 8 shows that the nanoparticle volume fraction decreases by accelerating the Brownian motion parameter $N b$. This holds practically because with an increase in $N b$ the random motion collusion of the macroscopic particles of the fluid increases. This reduces the concentration of the fluid, also the Brownian motion parameter $N b$ decreases the concentration boundary layer thickness.

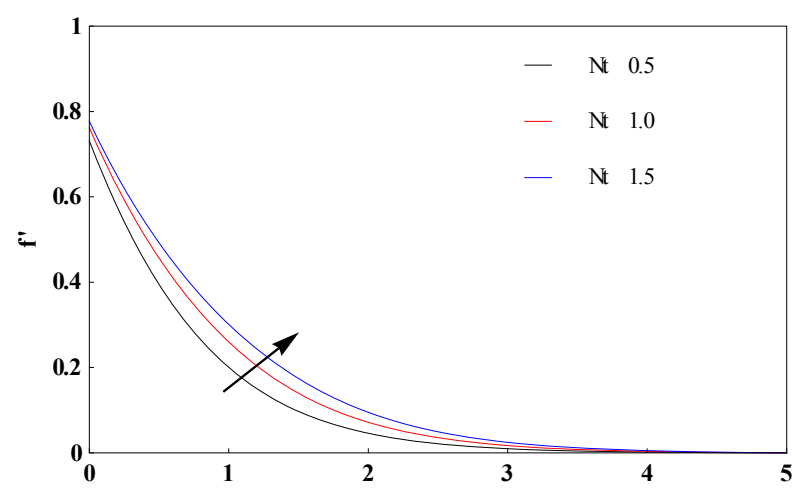

Fig.7a. Effect of the thermophoresis parameter on velocity profiles.

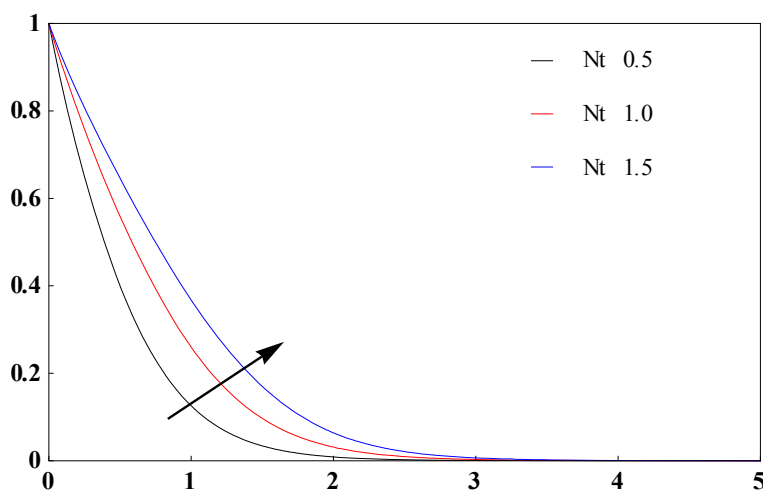

Fig.7b. Effect of the thermophoresis parameter on temperature profiles. 


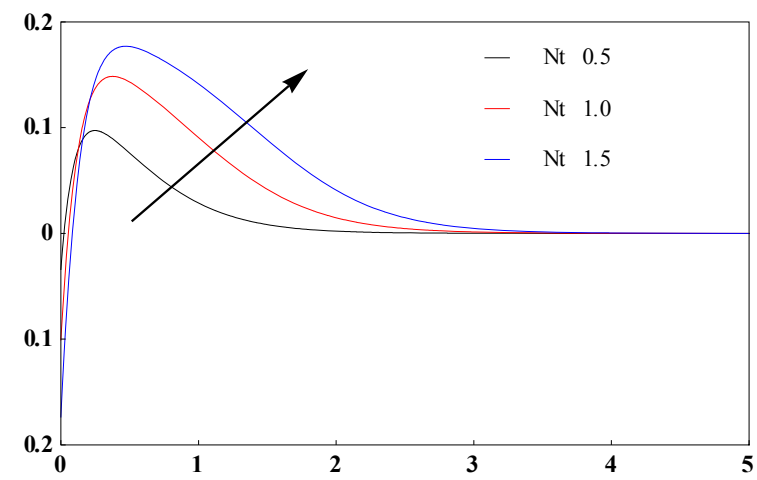

Fig.7c. Effect of the thermophoresis parameter on nanoparticle volume fraction profiles.

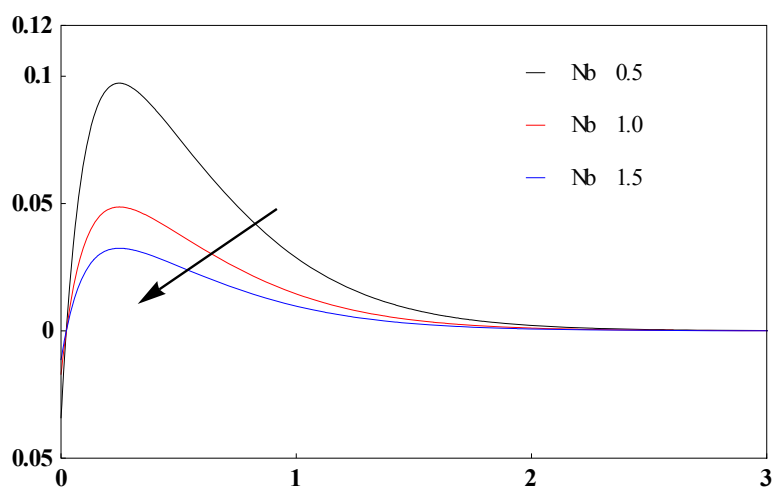

Fig.8. Effect of the Brownian motion parameter on nanoparticle volume fraction profiles.

Figure 9 shows the effect of the Lewis number Le on the nanoparticle volume fraction. The increasing Le number the nanoparticle volume fraction decreases and boundary layer thickness decreases. This is due to the fact that the mass transfer rate increases. The increasing Lewis number Le which enhances volume fraction nanoparticle.

Figures 10a-10c and 11a-11c depict the variation of the thermal Grashof number Gr and the solutal Grashof number Gc on velocity, temperature and nanoparticle volume fraction profiles, respectively. It is noticed that an increase in the momentum boundary layer thickness and increasing velocity profiles accompanies with an increasing Gr and Gc. The temperature as well as the nanoparticle volume fraction profiles decrease with increasing the values of Gr and Gc. The thermal Grashof number Gr signifies the relative effect of the thermal buoyancy force to the viscous hydrodynamic force in the boundary layer as expecting it is noticed that there is a rise in the velocity profiles due to the enhancement of thermal buoyancy force. The solutal Grashof number Gc defines the ratio of the species buoyancy force to the viscous hydrodynamic force due to increasing the species buoyancy force there is an increasing the velocity.

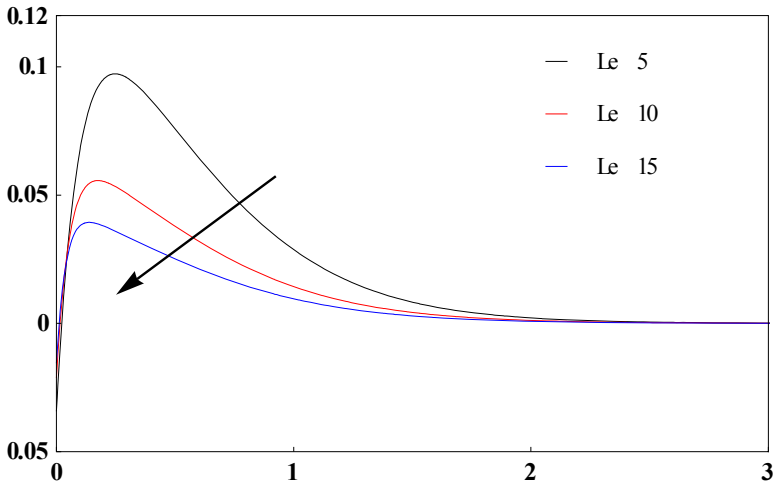

Fig.9. Effect of the Lewis number on nanoparticle volume fraction profiles.

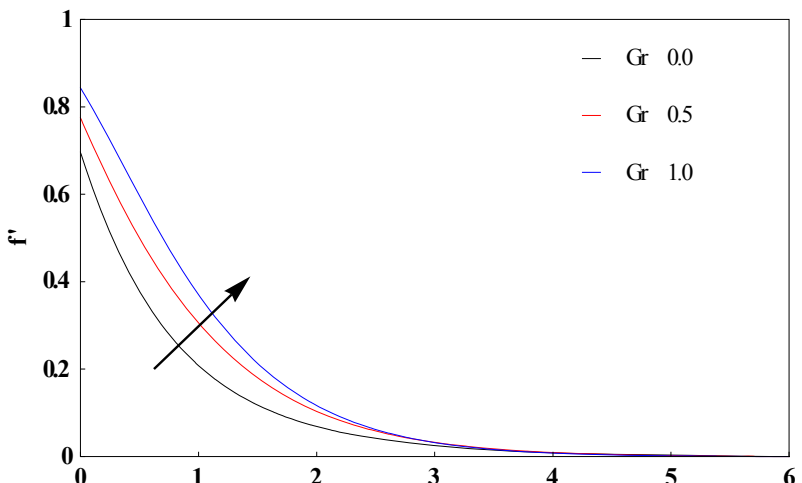

Fig.10a. Effect of the thermal Grashof number on velocity profiles. 


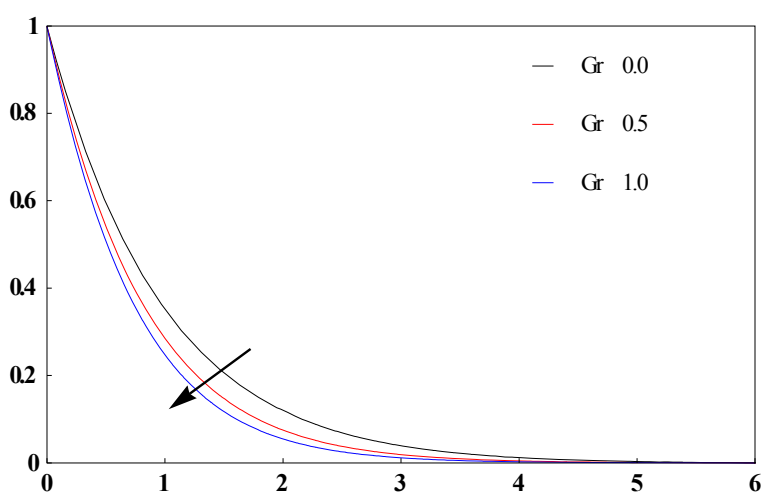

Fig.10b. Effect of the thermal Grashof number on temperature profiles.

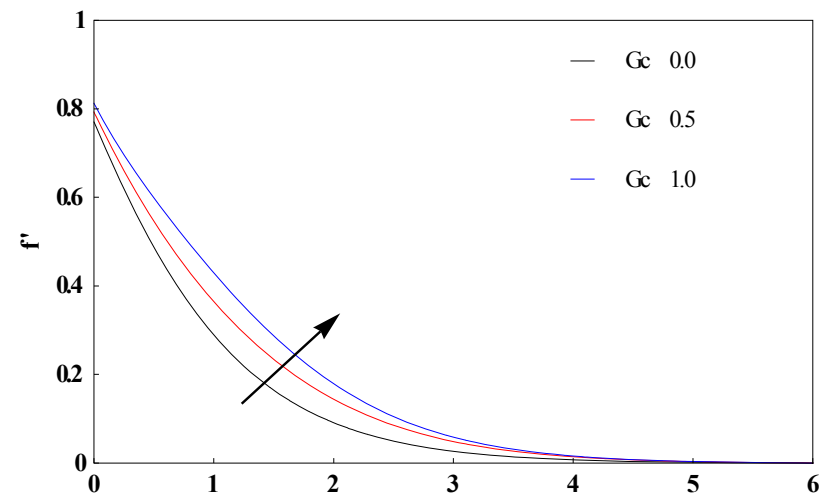

Fig.11a. Effect of the solutal Grashof number on velocity profiles.

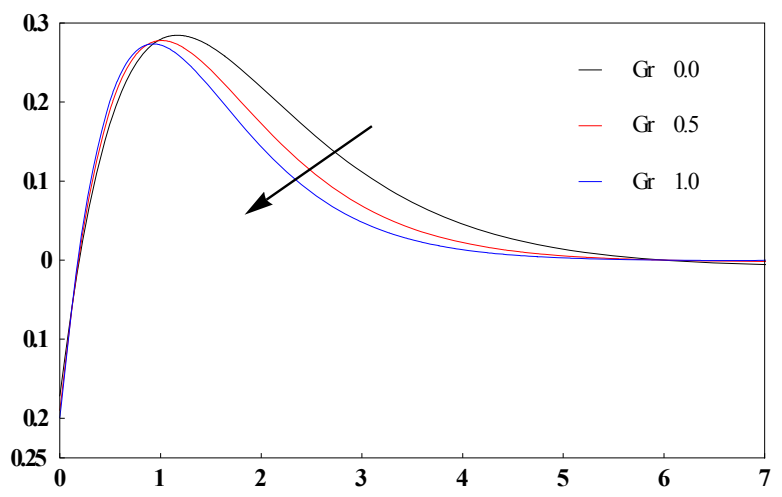

Fig.10c. Effect of the thermal Grashof number on nanoparticle volume fraction profiles.

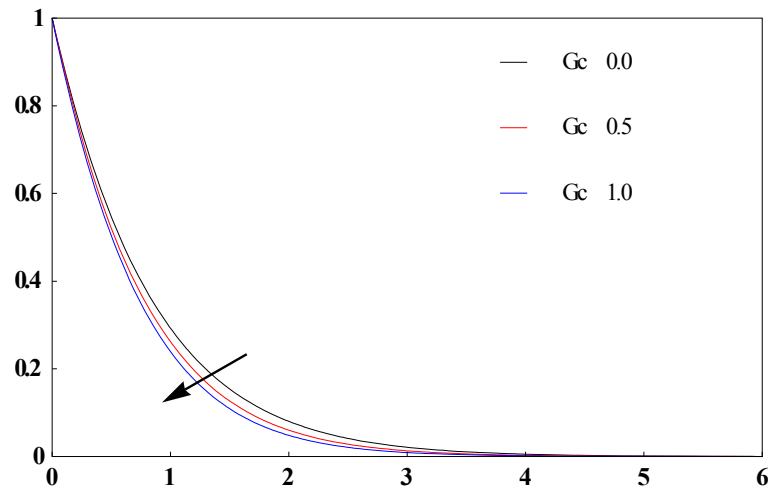

Fig.11b. Effect of the solutal Grashof number on temperature profiles.

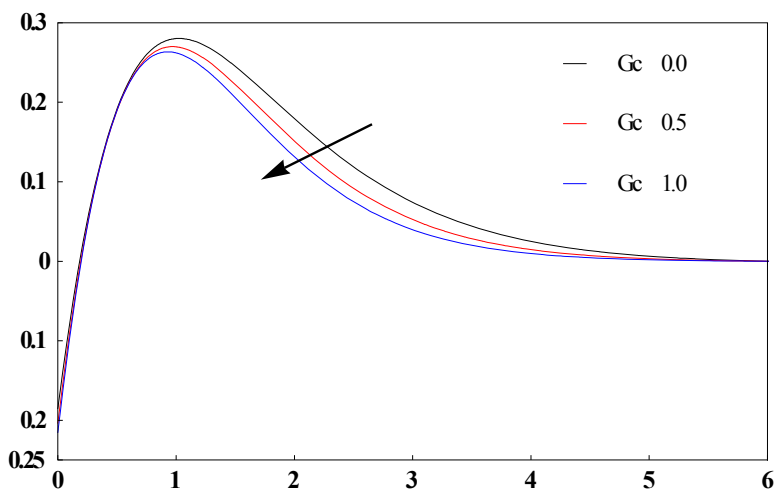

Fig.11c. Effect of the solutal Grashof number on nanoparticle volume fraction profiles.

The variations of dimensionless quantities, such as the local skin friction coefficient, local Nusselt number and local Sherwood number, for different values of physical parameters $n, M e$, $M$, $\zeta, \varepsilon, \delta, \operatorname{Pr}, N t, N b, \mathrm{Le}, \mathrm{Gr}, \mathrm{Gc}$ are shown in Tab.2. It can be noticed that the skin-friction value decreases with the increase of $n, \delta, M e, M, N b$, Le whereas it increases with increasing the value of 
$\zeta, \varepsilon, \operatorname{Pr}, N t, \mathrm{Gr}, \mathrm{Gc}$. The local Nusselt number decreases with increasing the value of $n, M, \zeta, N t, N b$, Le while it increases with $M e, \varepsilon, \delta, \operatorname{Pr}, \mathrm{Gr}$ and Gc.

Table 2. Numerical values of the local skin friction coefficient and local Nusselt number for different values of $n, M e, M, \zeta, \varepsilon, \delta, \operatorname{Pr}, N t, N b, \mathrm{Le}, \mathrm{Gr}, \mathrm{Gc}$.

\begin{tabular}{|c|c|c|c|c|c|c|c|c|c|c|c|c|c|}
\hline$n$ & $M e$ & $M$ & $\zeta$ & $\varepsilon$ & $\delta$ & $\mathrm{Pr}$ & $N t$ & $\mathrm{Nb}$ & Le & $G r$ & $G c$ & $C_{f_{x}}$ & $-\theta^{\prime}(0)$ \\
\hline 0.1 & 0.5 & 0.5 & 0.3 & 0.2 & 0.2 & 2 & 0.2 & 0.2 & 1 & 0.2 & 0.2 & -0.8769320 & 1.6095227 \\
\hline 0.5 & & & & & & & & & & & & -0.8966525 & 1.4726219 \\
\hline 1.0 & & & & & & & & & & & & -0.9105113 & 1.3746093 \\
\hline 0.1 & 0.1 & & & & & & & & & & & -0.7935226 & 1.2361965 \\
\hline & 0.3 & & & & & & & & & & & -0.8257680 & 1.3901869 \\
\hline & 0.5 & & & & & & & & & & & -0.8769320 & 1.6095227 \\
\hline & 0.5 & 0 & & & & & & & & & & -0.6025063 & 1.8110483 \\
\hline & & 0.4 & & & & & & & & & & -0.8329334 & 1.6435458 \\
\hline & & 0.8 & & & & & & & & & & -0.9891846 & 1.5196803 \\
\hline & & 0.5 & 0.2 & & & & & & & & & -0.9610876 & 1.6769677 \\
\hline & & & 0.3 & & & & & & & & & -0.8538096 & 1.6095227 \\
\hline & & & 0.4 & & & & & & & & & -0.7684520 & 1.5543778 \\
\hline & & & 0.3 & 0.1 & & & & & & & & -0.9005724 & 1.6054187 \\
\hline & & & & 0.3 & & & & & & & & -0.8122373 & 1.6126975 \\
\hline & & & & 0.5 & & & & & & & & -0.7415375 & 1.6169022 \\
\hline & & & & 0.2 & 0.2 & & & & & & & -0.8538096 & 1.6095227 \\
\hline & & & & & 1.0 & & & & & & & -0.8628244 & 1.6085893 \\
\hline & & & & & 1.8 & & & & & & & -0.8725477 & 1.6076003 \\
\hline & & & & & 0.2 & 0.7 & & & & & & -0.8850943 & 0.9019572 \\
\hline & & & & & & 1.4 & & & & & & -0.8785530 & 1.3338289 \\
\hline & & & & & & 2.1 & & & & & & -0.8767173 & 1.6499348 \\
\hline & & & & & & 2 & 0.1 & & & & & -0.8983398 & 1.6530801 \\
\hline & & & & & & & 0.2 & & & & & -0.8769320 & 1.6095227 \\
\hline & & & & & & & 0.3 & & & & & -0.8575574 & 1.5687999 \\
\hline & & & & & & & 0.2 & 0.1 & & & & -0.8488078 & 1.6412756 \\
\hline & & & & & & & & 0.2 & & & & -0.8769320 & 1.6095227 \\
\hline & & & & & & & & 0.3 & & & & -0.8867819 & 1.5979806 \\
\hline & & & & & & & & 0.2 & 1 & & & -0.8769320 & 1.6095227 \\
\hline & & & & & & & & & 3 & & & -0.8828147 & 1.5064577 \\
\hline & & & & & & & & & 5 & & & -0.8841778 & 1.4656549 \\
\hline & & & & & & & & & 1 & 0.2 & & -0.8769320 & 1.6095227 \\
\hline & & & & & & & & & & 0.4 & & -0.7937235 & 1.6651801 \\
\hline & & & & & & & & & & 0.6 & & -0.7144982 & 1.7149700 \\
\hline & & & & & & & & & & 0.2 & 0.0 & -0.9073748 & 1.5730432 \\
\hline & & & & & & & & & & & 0.1 & -0.8918116 & 1.5919943 \\
\hline & & & & & & & & & & & 0.2 & -0.8769320 & 1.6095227 \\
\hline
\end{tabular}




\section{Conclusions}

This present investigation is a worthwhile attempt to study the problem which involves MHD flow and heat transfer for non-Newtonian Powell-Eyring nanofluid flow past a nonlinear stretching sheet with slip velocity. Suitable dimensionless transformations are used to change the governing partial differential equations into ordinary ones. These equations were solved numerically by using the shooting method. The results were presented graphically and the effects of the emerging flow parameters on velocity, temperature and nanoparticle volume fraction profiles and discussed in detail with physical interpretations. It is found that the flow parameters $n, M e, M, \zeta$ reduce the non-dimensional velocity profiles $f^{\prime}$ whereas the velocity profiles $f^{\prime}$ increase with the increase of $\varepsilon, \operatorname{Pr}, N t, \mathrm{Gr}, \mathrm{Gc}$. The effect of $\zeta, n$ enhances both the temperature and nanoparticle volume fraction profiles. It is noticed that as $\mathrm{Me}, \mathrm{Pr}, \mathrm{Gr}, \mathrm{Gc}$ increase the temperature and nanoparticle volume fraction profiles decrease as the effect of non-Newtonian fluid parameter $\delta$ then enhances the temperature profiles. The effect of the magnetic field parameter $M$ is to enhance the temperature and nanoparticle volume fraction profiles, as the effect of thermophoresis parameter $N t$ is to enhance the temperature and nanoparticle volume fraction profiles, whereas the nanoparticle volume fraction profiles decrease with the increase of $N b$ and Le. Finally, it is found that the skin friction coefficient value decreases with the increase of the values $n, \delta, M e, M, \mathrm{Nb}$, Le, while it increases with $\zeta, \varepsilon, \mathrm{Pr}, N t, \mathrm{Gr}, \mathrm{Gc}$. It is also seen that the heat transfer coefficient $-\theta^{\prime}(\theta)$ value decreases with increasing the values of $n, M, \zeta, N t, \mathrm{Nb}$, Le while it increases with increasing values of $M e, \varepsilon, \delta, \operatorname{Pr}, \mathrm{Gr}$ and Gc.

\section{Nomenclature}

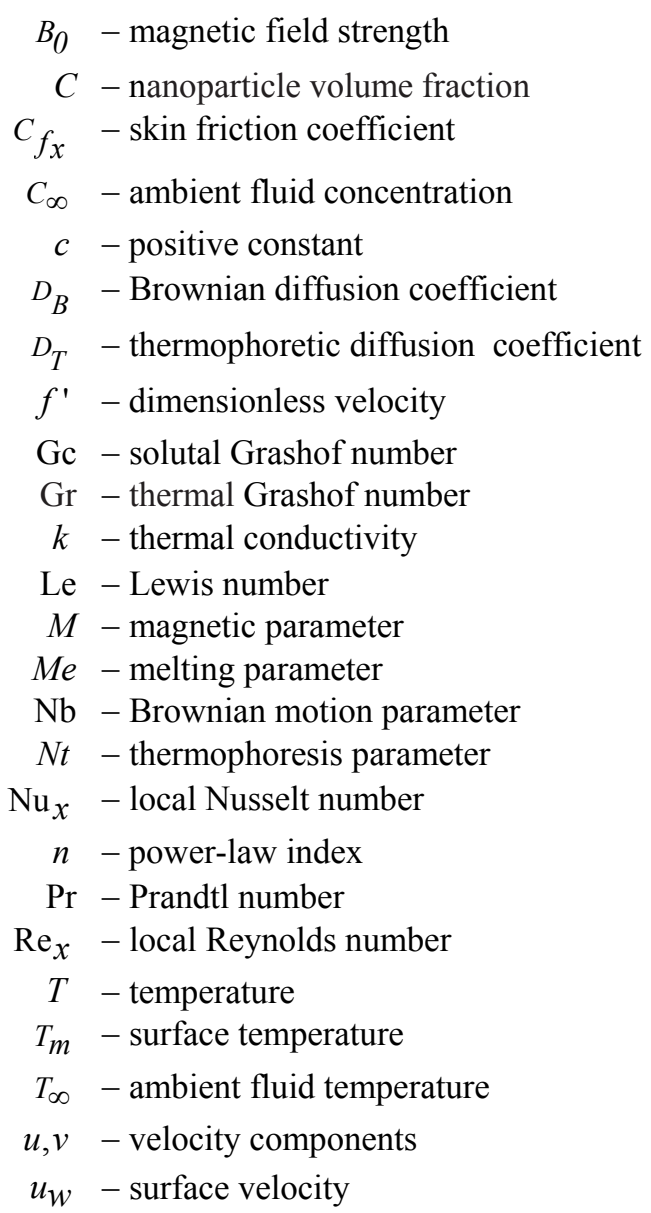




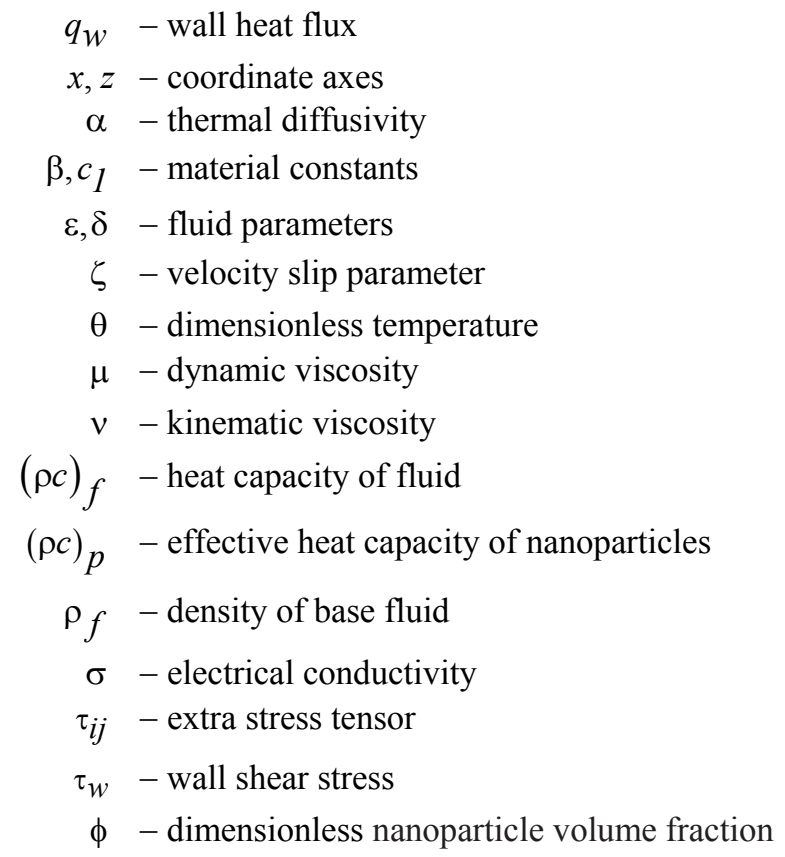

\section{References}

[1] Crane L.J. (1970): Flow past a stretching plate. - Zeitschrift fur Angewandte Mathematik und Physik, vol.21, pp.645-641.

[2] Vleggaar J. (1977): Laminar boundary layer behaviour on continuous accelerating surface. - Chem. Eng. Sci., vol.32, pp.1517-1525.

[3] Crane L.J. (1970): Flow past a stretching plate. - J. Appl. Math. Phys. (ZAMP), vol.21, pp.645-647.

[4] Wang C.Y. (1984): The three-dimensional flow due to a stretching flat surface. - Phys. Fluids, vol.27, pp.19151917.

[5] Andersson H.I. and Dandapat B.S. (1991): Flow of a power-law fluid over a stretching sheet. - SAACM 1, pp.339347.

[6] Magyari E. and Keller B. (2000): Exact solutions for self-similar boundary-layer flows induced by permeable stretching walls. - Eur. J. Mech. B Fluids, vol.19, pp.109-122.

[7] Sparrow E.M. and Abraham J.P. (2005): Universal solutions for the stream wise variation of the temperature of a moving sheet in the presence of a moving fluid. - Int. J. Heat Mass Transfer, vol.48, pp.3047-3056.

[8] Hunegnaw Dessie and Naikoti Kishan (2014): MHD effects on heat transfer over stretching sheet embedded in porous medium with variable viscosity, viscous dissipation and heat source/sink. - Ain Shams Engineering Journal, vol.26, pp.967-977.

[9] Kishan N. and Amrutha P. (2011): Effects of viscous dissipation on MHD flow with heat and mass transfer over a stretching surface with heat source, thermal stratification and chemical reaction. - Journal of Naval Architecture and Marine Engineering, vol.7, No.1, pp.11-18.

[10] Turkyilmazoglu M. (2012): Dual and triple solutions for MHD slip flow of non-Newtonian fluid over a shrinking surface. - Comput. Fluids, vol.70, pp.53-58.

[11] Yin C., Niu J., Fu C. and Tan W.C. (2013): Thermal convection of a viscoelastic fluid in a fluid-porous system subjected to horizontal plane Couette flow. - Int. J. Heat Fluid Flow, vol.44, pp.711-718. 
[12] Makinde O.D., Chinyoka T. and Rundora L. (2011): Unsteady flow of a reactive variable viscosity non-Newtonian fluid through a porous saturated medium with asymmetric convective boundary conditions. - Comput. Math. Appl., vol62, pp.3343-3352.

[13] Ellahi R. (2013): The effects of MHD and temperature dependent viscosity on the flow of non-Newtonian nanofluid in a pipe: Analytical solutions. - Appl. Math. Model., vol.37, pp.1451-1467.

[14] Srinivas Reddy C. and Kishan N. (2015): MHD Boundary layer flow and heat transfer of a nanofluid over a shrinking sheet with mass suction and chemical reaction. - Journal of Nanofluids, vol.4, pp.518-527.

[15] Madhu M. and Kishan N. (2016): Finite element analysis of heat and mass transfer by MHD mixed convection stagnation-point flow of a non-Newtonian power-law nanofluid towards a stretching surface with radiation. Journal of the Egyptian Mathematical Society, vol.24, No.3, pp.458-470.

[16] Madhu M., Kishan N. and Chamka A. (2016): Boundary layer flow and heat transfer of a non-Newtonian nanofluid over a non-linearly stretching sheet. - International Journal of Numerical Methods for Heat and Fluid Flow, vol.26, No.7, pp.2198-2217.

[17] Madhu M. and Kishan N. (2016): MHD boundary-layer flow of a non-Newtonian nanofluid past a stretching sheet with a heat source/sink. - Journal of Applied Mechanics and Technical Physics, vol.57, No.5, pp.908-915.

[18] Patel M. and Timol M.G. (2009): Numerical treatment of Powell-Eyring fluid flow using method of satisfaction of asymptotic boundary conditions (MSABC). - Appl. Numer. Math., vol.59, pp.2584-2592.

[19] Hayat T., Iqbal Z., Qasim M. and Obidat S. (2012): Steady flow of an Eyring Powell fluid over a moving surface with convective boundary conditions. - Int. J. Heat Mass Transf., vol.55, pp.1817-1822.

[20] Rosca A.V. and Pop I.M. (2014): Flow and heat transfer of Powell-Eyring fluid over a shrinking surface in a parallel free stream. - Int. J. Heat Mass Transfer, vol.71, pp.321-327.

[21] Jalil M., Asghar S. and Imran S.M. (2013): Self similar solutions for the flow and heat transfer of Powell-Eyring fluid over a moving surface in a parallel free stream. - Int. J. Heat Mass Transfer, vol.65, pp.73-79.

[22] Islam S., Shah A., Zhou C.Y. and Ali I. (2009): Homotopy perturbation analysis of slider bearing with PowellEyring fluid. -Z. Angew. Math. Phys., vol.60, pp.1178-1193.

[23] Sirohi V., Timol M.G. and Kalathia N.L. (1984): Numerical treatment of Powell-Eyring fluid flow past a 90 degree wedge. - Reg. J. Energy Heat Mass Transfer, vol.6, No.3, pp.219-228.

[24] Powell R.E. and Eyring H. (1944): Mechanism for relaxation theory of viscosity. - Nature, vol.154, pp.427-428.

[25] Hayat T., Iqbal Z., Qasim M. and Obaidat S. (2012): Steady flow of an Eyring-Powell fluid over a moving surface with convective boundary conditions. - Int. J. Heat Mass Transfer, vol.55, pp.1817-1822.

[26] Choi S.U.S. and Eastman J.A. (1995): Enhancing thermal conductivity of fluids with nanoparticles. - Exposition. ASME, San Francisco, USA, FED 231/MD66, pp.99-105.

[27] Khan W.A. and Pop I. (2010): Boundary layer flow of a nanofluid past a stretching sheet. - Int. J. Heat Mass Transfer, vol.53, pp.2477-2483.

[28] Kuznetsov A.V. and Nield D.A. (2010): Natural convective boundary-layer flow of a nanofluid past a vertical plate. - Int. J. Therm. Sci., vol.49, pp.243-247.

[29] Gorla R.S.R., Kabeir S.M.M.E.L, and Rashad A.M. (2011): Heat transfer in the boundary layer on a stretching circular cylinder in a nanofluid. - J. Thermophys. Heat Transfer, vol.25, pp.183-186.

[30] Aziz A. (2010): Hydrodynamic and thermal slip flow boundary layers over a flat plate with constant heat flux boundary condition. - Comm. Nonlinear Num. Simu., vol.15, pp.573-580.

[31] Nield D.A. and Kuznetsov A.V. (2006): Forced convection with slip-flow in a channel or duct occupied by a hyper-porous medium saturated by a rarefied gas. - Transp. Porous Media, vol.64, pp.161-170.

[32] Beavers G.S. and Joseph D.D. (1967): Boundary condition at a naturally permeable wall. - J. Fluid Mech., vol.30, pp.197-207. 
[33] Hamdan M.A., Al-Nimr M.A. and Hammoudeh V.A. (2010): Effect of second order velocity-slip/temperaturejump on basic gaseous fluctuating micro-flows. - J. Fluids Eng., vol.132, 074503.

[34] Bhattacharyya K., Mukhopadhyay S. and Layek G.C. (2011): Slip effects on boundary layer stagnation-point flow and heat transfer towards a shrinking sheet. - Int. J. Heat Mass Transfer, vol.54, pp.308-313.

[35] Roberts L. (1958): On the melting of a semi-infinite body of ice placed in a hot stream of air. - J. Fluid Mech., vol.4, pp.505-528.

[36] Hayat T., Farooq M. and Alsaedi A. (2014): Melting heat transfer in the stagnation point flow of Maxwell fluid with double diffusive convection. - Int. J. Numer. Methods Heat Fluid Flow, vol.24, pp.760-774.

[37] Das K. (2014): Radiation and melting effects on MHD boundary layer flow over a moving surface. - Ain Shams Eng. J., vol.5, pp.1207-1214.

[38] Epstein E.M. and Cho D.H. (1976): Melting heat transfer in steady laminar flow over a flat plate. - J. Heat Transfer, vol.98, pp.531-533.

[39] Kazmierczak M., Poulikakos D. and Pop I. (1986): Melting from a flat plate embedded in a porous medium in the presence of steady convection. - Numer. Heat Transfer, vol.10, pp.571-581.

[40] Gorla R.S.R., Mansour M.A., Hussanien I.A. and Bakier A.Y. (1999): Mixed convection effect on melting from a vertical plate. - Transport Porous Med., vol.36, pp.245-254.

[41] Bachock N., Ishak A. and Pop I. (2010): Melting heat transfer in boundary layer stagnation point flow towards a stretching/shrinking sheet. - Phys. Lett. A 374, pp.4075-4079.

[42] Anuar Ishak and Roslinda Nazar (2010): Melting heat transfer in steady laminar flow over a moving surface. Heat Mass Transfer, vol.46, pp.463-468.

[43] Gireesha B.J., Mahanthesh B., Shivakumara I.S. and. Eshwarappa K.M. (2016): Melting heat transfer in boundary layer stagnation-point flow of nanofluid toward a stretching sheet with induced magnetic field. - Engineering Science and Technology an International Journal, vol.19, pp.313-321.

[44] Chamkha A.J., Rashad A.M. and Al-Meshaiei E. (2011): Melting effect on unsteady hydrodynamic flow of a nanofluid past a stretching sheet. - Int. J. Chem. React. Eng., vol.9, pp.1-13.

[45] Gorla R.S.R., Chamkha A. and Aloraier A. (2011): Melting heat transfer in a nanofluid flow past a permeable continuous moving surface. - J. Nav. Arch. Mar. Eng., vol.2, pp.83-92.

[46] Panigrahi S., Reza M. and Mishra A.K. (2014): MHD effect of mixed convection boundary-layer flow of PowellEyring fluid past nonlinear stretching surface. - Vol.35, No.12, pp.1525-1540.

[47] Cortell R. (2007): Viscous flow and heat transfer over a nonlinearly stretching sheet. - Applied Mathematics and Computation, vol.184, pp.864-873.

[48] Rana P. and Bhargava R. (2012): Flow and heat transfer of a nanofluid over a nonlinearly stretching sheet: A numerical study. - Communications in Nonlinear Science and Numerical Simulation, vol.17, pp.212-226.

Received: March 14, 2017

Revised: July 30, 2018 